\title{
BIOGRAFIA MÚSICO-EDUCATIVA: ASPECTOS TEÓRICOS E METODOLÓGICOS
}

\author{
Music-educational biographytheoretical \\ and methodological aspects
}

\author{
Biografía músico-educativa: aspectos \\ teóricos y metodológicos
}

\author{
JÉSSICA DE ALMEIDA \\ Universidade Federal de Roraima \\ almeidadejessica@gmail.com
}

\author{
ANA LÚCIA LOURO \\ Universidade Federal de Santa Maria \\ analouro@brturbo.com.br
}

\begin{abstract}
Resumo: O artigo tem o objetivo de apresentar a biografia músico-educativa como procedimento metodológico de pesquisa e como uma alternativa para a formação de educadores musicais. Ancora-se em uma discussão teórica desenvolvida no âmbito de uma pesquisa de doutorado que visou compreender as maneiras por meio das quais as biografias músico-educativas de licenciandos em Música produziram sentidos para seus processos formativos. A biografia músico-educativa, nesse contexto, foi procedimento de pesquisa e metodologia de formação, pois, ao mesmo tempo que possibilitou um acesso calculado aos horizontes de significados dos sujeitos sobre música e educação musical em suas vidas relacionados às suas formações, permitiu que os sujeitos refletissem sobre suas trajetórias acadêmicas, bem como sobre o lugar de cada um enquanto sujeito de sua própria formação. Por meio desse artigo, espera-se contribuir com a área de educação musical somando a pesquisadores que há quinze anos discutem as implicações da pesquisa (auto)biográfica em diversos contextos de pesquisa.
\end{abstract}

Palavras-chave: Pesquisa (auto)biográfica. Biografia educativa. Formação docente.

\begin{abstract}
The article aims to present the music-educational biography as a methodological research procedure and also as an alternative music teacher education. It is anchored in a theoretical discussion developed within the scope of a doctoral research that aimed to understand the ways that music-educational biographies of students of undergraduate course of music teacher training produced meanings for their formative processes. The musiceducational biography, in this context, was a research procedure and training methodology, because, at the same time, it provided a calculated access to the horizons of the subjects' meanings about music and music education in their lives related to their formations, subjects reflect on their academic trajectories as well as on the place of each as subject of their own formation. This article hopes to contribute to the Music Education side by side with researchers who in the past fifteen years discuss the implications of (auto)biographical research in various research contexts of Music and Music Education.
\end{abstract}

Keywords: (Auto)biographical research. Educational biography. Teacher training.

Resumen: El artículo tiene el objetivo de presentar la biografia músico-educativa como procedimiento metodológico de la investigación y como una alternativa a la formación de educadores musicales. Está anclado en un debate teórico desarrollado en el marco de una investigación de doctorado que objetivó a entender las formas en que las biografias músicoeducativas de los licenciandos de música produjeron sentidos para sus procesos formativos. La biografia músico-educativa, en este contexto, fue el procedimiento de búsqueda y la metodología de capacitación, porque, al mismo tiempo que permitió acceder de forma calculada sobre los horizontes de los sujetos de las asignaturas de música y educación musical en sus vidas relacionadas con sus formaciones, permitió que los sujetos reflexionaran sobre sus trayectorias académicas, así como sobre el lugar de cada uno como sujeto de su propia formación. A través de este artículo, se espera contribuir a la esfera de la educación musical, sumado a los investigadores que hace quince años discuten las implicaciones de la investigación (auto)biográfica en diversos contextos de investigación.

Palabras clave: Investigación (auto)biográfica. Biografia Educativa. La formación docente. 


\section{INTRODUÇÃO}

Ao refletir-se sobre a multiplicidade de caminhos músico-educativos que repercutem no interesse em cursar Licenciatura em Música, melodias vêm à memória, cenas musicais, cirandas, celebrações, lembranças do primeiro contato com um instrumento musical... imagens que carregamos por toda a vida e que, ao escolhermos a música como profissão, podem ser ressignificadas, funcionar como verdadeiros refúgios ou, em outros casos, podem ser dissipadas, negadas, postas em questão.

A biografia músico-educativa, enquanto procedimento de pesquisa e formação, ${ }^{1}$ pode ser desenvolvida com pequenos grupos constituídos por sujeitos em formação (disciplina da graduação, curso de férias, curso de formação continuada, por exemplo) e está organizada a partir de um prémomento, seguindo-se de quatro momentos com atividades individuais e coletivas. Os diferentes momentos, que incluem dois encontros presenciais, debruçam-se sobre a organização de narrativas orais, sobre a discussão de pontos consonantes e de outras perspectivas sobre o narrado. Além disso, no final do procedimento, organiza-se a escrita de uma produção final, uma biografia músico-educativa, reunindo o estudo sobre suas próprias narrativas, reflexões sobre os momentos de socialização com os demais participantes e percepções sobre o procedimento metodológico.

Esses sentidos e interpretações atribuídas às experiências narradas no decorrer das etapas que constituem a biografia músico-educativa podem ser evidenciados por meio do estudo fundamentado na Espiral Retroativa do Caminho para Si (Josso, 2010a). No caso da pesquisa de doutorado que fundamenta este artigo, primeira investigação que estudou biografias músico-educativas, foi possível perceber que a) a compreensão dos processos formativos acadêmicos significados a partir das experiências de aprendizagem musical ocorridas em contextos religiosos (igreja), em contextos não formais (fanfarras) e em outras experiências cotidianas (como o aprendizado musical através de bandas de música ou as trocas musicais entre colegas de escola no recreio) foram possibilitadas por meio de biografias músico-educativas; b) alguns conhecimentos músico-educativos obtidos ao longo da vida, sobretudo os instrumentais e pragmáticos, acabam sendo silenciados, principalmente, quando contestados a partir do contato com conhecimentos mais formalizados, institucionalizados; c) os conhecimentos que fundamentam referenciais para interpretação de realidades e situações vividas operam como verdadeiros refúgios nos quais os acadêmicos buscam subsídios para entender o quanto sabem, ou não

\footnotetext{
${ }^{1}$ A pesquisa de doutorado que fundamenta este texto discutiu os sentidos produzidos por biografias músicoeducativas em processos formativos de alunos de um curso de Licenciatura em Música da região Norte do Brasil (Almeida, 2019). Nesse contexto, tais exemplos de características dos múltiplos caminhos mencionados acima foram emergidos de uma dinâmica de pesquisa e formação intersubjetiva, coletiva. Esta última, chamada de biografia músico-educativa, é tomada como objeto deste artigo.
} 
sabem, na graduação; e que d) as aprendizagens e conhecimentos existenciais, dinâmicas, atitudes e qualidades dos sujeitos revelaram processos de conscientização por parte dos participantes da pesquisa.

\section{CAMINHOS TEÓRICO-METODOLÓGICOS DA BIOGRAFIA MÚSICO- EDUCATIVA}

O acesso a interpretações, significados e valores sobre experiências músico-educativas foi possivel por meio de uma metodologia de pesquisa (auto)biográfica que adotou o método biográfico história de vida para estudar narrativas de licenciandos em Música produzidas por meio do procedimento biografia músico-educativa.

Nesse sentido, o conceito narrativa se apresentou como fundamentação teórica, na qual buscou-se constituir um modo de pensamento e organização do conhecimento e de entendimento da realidade (Bolivar; Domingo; Fernández, 2001). Além disso, a narrativa também delineou-se como fenômeno investigado, tendo em vista a compreensão de perspectivas dos diferentes processos que permearam a produção narrativa dos sujeitos, as relações estabelecidas entre memória, discurso e reflexividade, bem como os seus lugares de fala e territórios de cada um (Cunha, 2008), por exemplo.

Assim, como "modo de pensar, de organizar o conhecimento e a realidade" 2 (Bolivar; Domingo; Fernández, 2001, p. 19, tradução nossa), a narrativa pode ser formadora quando materializa uma parte da vida na qual o sujeito esteve implicado em um processo de formação, ou seja, de transformação, de mudança de paradigmas, de incorporação de novos conceitos e perspectivas às suas interpretações, de descoberta de novos horizontes e significados para as experiências narradas (Chiené, 2010).

Nesse sentido, a biografia músico-educativa se debruça em estudar coletivamente narrativas de formação, pois, no decorrer de encontros presenciais, estimula a produção narrativa sobre experiências com a música e com a educação musical em diferentes espaços que, de alguma forma, se relaciona com as experiências do contexto institucionalizado de formação (universidade, curso de férias, etc.). Assim, por meio das diferentes etapas da biografia músico-educativa, os sujeitos participantes não só organizam os eventos na narrativa, como também envolvem-se em um processo de transformação, seja a partir da implicação dos sujeitos na própria história de vida (Lani-Bayle, 2012), seja a partir da construção de sentido, percebendo e significando a experiência de acordo com as estruturas narrativas, como inscrição das narrativas em temporalidades (Bolivar; Domingo; Fernández, 2001; Lani-Bayle, 2012), seja pelo processo de conscientização (Josso, 2010a), para citar alguns exemplos.

\footnotetext{
2 "un modo básico de pensamiento, de organizar el conocimiento y la realidad" (Bolívar; Domingo; Fernández, 2001, p. 19).
} 
Por essas e outras razões, a narrativa tem sido explorada, também, pela educação musical enquanto modalidade de pesquisa (Anders, 2014; Soares, 2014; Teixeira, 2016), procedimento metodológico (Anders, 2014; Machado, 2014; Pereira, 2016; Soares, 2014; Souza, 2013; Teixeira, 2016), fenômeno investigado (Pereira, 2016; Soares, 2014) e procedimento de análise (Soares, 2014), prevalecendo, segundo estudo realizado na investigação que fundamenta este artigo, o uso de narrativas como forma de relato (Anders, 2014; Façanha, 2017; Fonseca, 2016; Gaulke, 2013; Neto, 2014; Pereira, 2016; Soares, 2014; Teixeira, 2016; Weiss, 2015). Além disso, é comum a concomitância de diferentes funções da narrativa nas pesquisas, que pode ser observada pela recorrência de teses e dissertações nas diferentes categorias anteriormente listadas.

Vale destacar, nesse contexto, o trabalho desenvolvido pela pesquisadora e professora Ana Lúcia Louro, que há quinze anos estuda as aplicações das narrativas em pesquisas científicas e em contextos formativos. Sobre o entendimento das narrativas nos contextos das pesquisas desenvolvidas e orientadas pela referida professora, é possivel observar três perspectivas: como atividade integrante de um processo intersubjetivo aplicado à formação docente (Louro, 2008; Louro, 2013; Reck; Louro; Rapôso, 2014; Almeida; Louro, 2016; Louro; Teixeira; Reck, 2016; Louro, 2016; Louro; Reck, 2017); como relatos, entendendo que a perspectiva acima não exclui o entendimento da narrativa também como relato, a partir dos quais se deram a conhecer concepções sobre educação e música (Louro; Aróstegui, 2003), sobre a formação e a prática docente (Almeida; Louro, 2016; Louro; Reck, 2017), sobre alguns temas que constituem lembranças e memórias de alunos e professores de música (Louro; Teixeira; Reck, 2016) e sobre espaços de educação musical (Reck; Louro; Rapôso, 2014), entre outros.

Formando um coro - às vezes em uníssono, ora em polifonia, mas nunca em dissonância -, outros pesquisadores da área de Música e de educação musical têm contribuído para a construção desse corpo metodológico e teórico que contempla narrativas. Entre eles, podemos destacar as produções das professoras e pesquisadoras Maria Cecília de Araújo Rodrigues Torres e Delmary Vasconcelos de Abreu, que, além de publicações recorrentes, têm orientado pesquisas que discutem, em seu corpo teórico, narrativas, entre outros conceitos. A primeira traz uma concepção de narrativa (narrativas de si, para a autora) como autobiografias musicais (Torres, 2003; 2004) e (auto)biografias musicais (Torres, 2017), termo que permeou a construção do entendimento sobre as narrativas musicais, que foram trabalhadas, igualmente, pela biografia músicoeducativa.

Em direção semelhante, Abreu (2011a; 2011b; 2011c; 2015) considerou narrativa como estratégia metodológica característica do campo das abordagens (auto)biográficas. A autora entende que "a narrativa fundamenta 
o modelo que inspira nossas representações biográficas e a maneira como narramos nossa vida. Fazer a narrativa de vida consiste em contar como o narrador é, ou como se tornou ou vem se tornando ao longo do tempo" (2011a, p. 149). Por esse motivo, buscou estudar narrativas de profissionalização para compreender o processo de profissionalização de professores que se tornaram professores de música, embora suas licenciaturas tenham sido em outras áreas do conhecimento.

Recentemente, Abreu (2017) apresentou os atos de musicobiografização, estes configurados como material biográfico para realizar análise em uma perspectiva (auto)biográfica. Nesse contexto, "as narrativas com música tornam potencialmente acessiveis os sistemas de tematização e de valorização utilizados pelo sujeito que faz narrativas de si com música" (p. 221).

A biografia músico-educativa aproxima-se de ambos os conceitos, musicobiografização e narrativas musicais/autonarrativas musicais/autobiografias musicais. O primeiro visa à compreensão dos modos de desenvolvimento dos indivíduos por meio de suas histórias de vida em formação com a música, o sentido da relação das pessoas com a música. Em direção semelhante, a biografia músico-educativa investiga a tomada de consciência sobre as representações e significados produzidos pela música nos processos formativos dos individuos, justamente um dos sentidos da relação das pessoas com a música. Além disso, próxima do segundo conceito, busca materializar, em narrativas, os processos formativos conscientizados por intermédio de uma atividade de formação.

Em outra direção, a biografia músico-educativa não focaliza apenas memórias com a música, como também outras possiveis memórias (escola, família, comunidade), que, ao lado da música, delinearam os caminhos que trouxeram os sujeitos em formação para um curso de licenciatura, por exemplo, e que subsidiam seus processos formativos também na graduação.

A materialização dessas experiências se dá na biografia músicoeducativa, por meio da elaboração de narrativas de si (narrativas musicais, no procedimento) e de narrativas entrelaçadas que emergiram, assim como as autonarrativas musicais/autobiografias musicais (Torres, 2003; 2004),

[...] memórias musicais da infância, adolescência e vida adulta com as lembranças de melodias, letras de músicas, shows de bandas, rituais religiosos, aulas de instrumentos musicais, grupos de amigos e familiares e práticas pedagógicas (Torres, 2003, p. 84).

Cada caminho teórico e metodológico percorrido por esses e outros autores revelam a pertinência da discussão sobre os usos, funções, limites e potencialidades da narrativa e da pesquisa (auto)biográfica para a educação musical e, também, para a formação de educadores musicais, discussões que, lentamente, têm ganhado espaço em publicações acadêmicas e 
científicas da área (Abreu, 2011a; Alves, 2015; Figueirôa, 2017; Gaulke, 2013; Lopes, 2014; Neto, 2014; Rasslan, 2014; Silva, 2016; Tavares, 2017; Vieira, 2017; Weber, 2014).

Por outro lado, o debate sobre pesquisa (auto)biográfica e sobre o método biográfico história de vida ainda encontra-se em fase embrionária, reflexo da flutuação conceitual das expressões e da própria pluralidade de exploração de suas funções. Ampliando o olhar para áreas próximas, como a Educação, pode-se conhecer uma prolífica produção científica de pesquisas qualitativas que revela um cenário teórico e metodológico plural quanto ao entendimento sobre histórias de vida e sobre pesquisa (auto)biográfica.

Assim, a primeira é entendida como método (Josso, 2016), abordagem de pesquisa e formação (Pineau; Legrand, 2012; Souza, 2016), perspectiva teórico-metodológica centrada nos processos formativos (Bragança, 2011) e como metodologia de pesquisa, sobretudo na pesquisa sociológica. Essa função metodológica pode ser observada no contexto educativo justamente por recuperar a sua "dimensão de instrumento de ação social [...] em alfabetização, em educação popular, em formação profissional contínua, em formação de formadores, em orientação e em desenvolvimento de projetos, em avaliações de competências e reconhecimento de aquisições experienciais" (Josso, 2016, s.p.). E, ainda, pelo fato de “[...] acompanhar, orientar, suscitar ou facilitar a elaboração dos projetos pessoais de indivíduos em busca de uma orientação ou de uma reorientação profissional [...]" (Peres, 2011, p. 177).

Como um dos fundamentos da biografia músico-educativa somado às contribuições epistemológicas da pesquisa (auto)biográfica, o método biográfico história de vida presidiu desde o preparo do ambiente para receber os sujeitos até o desenho de cada etapa da pesquisa, seguindo-se do registro das narrativas e do posterior estudo dessas vidas tecidas na pesquisa, processos que resultaram no procedimento tema deste artigo.

Por fim, a biografia músico-educativa desenvolveu-se a partir da modalidade de pesquisa e formação (auto)biográfica, pois utilizou-se de fontes (auto)biográficas (narrativas) e pautou-se em uma produção teórica internacional consolidada há mais de trinta anos que referencia grande parte das pesquisas (auto)biográficas educacionais brasileiras. ${ }^{3}$

Como uma forma de história autorreferente "em que o sujeito se desvela, para si, e se revela para os demais" (Abrahão, 2004, p. 202), destaca-se o trabalho da memória, em que a história de vida se insere como estrutura organizacional, como objetivo e como finalidade, acrescenta-se; e a

\footnotetext{
${ }^{3}$ Entre os autores quem compõem essa rede internacional (incluindo pesquisadores brasileiros) e que também fundamentaram a biografia músico-educativa, destacam-se alguns estudos de António Nóvoa (1995a; 1995b), Marie-Christine Josso (1999; 2010a; 2010b; 2010c, 2014; 2016), Maria da Conceição Passeggi (2011a; 2011b e outros), Maria Helena Menna Barreto Abrahão (2004; 2011; 2016) e Pierre Dominicé (2000; 2006; 2010a; 2010b).
} 
narrativa, como fonte e processo reflexivo-formativo, ambos elementos essenciais para o trabalho com pesquisa (auto)biográfica.

Somada a essa característica, ela adentra, também, espaços de formação profissional, tomando como ponto de partida a possibilidade de formar-se ao contar-se e refletir sobre si, além da necessidade de rompimento de modelos hegemônicos de formação. Alguns desses delineamentos metodológicos em contextos de formação acadêmica (Abrahão, 2011; Delory-Momberger, 2006; Josso, 2010a; Nacarato; Passeggi, 2013; Passeggi, 2002; Peres, 2008; 2010; 2011) foram estudados e aproximados com as atividades descritas na biografia músico-educativa.

Essa mesma rede teórica internacional, que referencia grande parte das pesquisas (auto)biográficas brasileiras, fundamentou a biografia músicoeducativa. Entre as produções, cabe destacar aquela que inspirou o nome e parte dos delineamentos teórico-metodológicos da biografia músicoeducativa: a biografia educativa, discutida, principalmente, por Pierre Dominicé (2000).

\section{DA BIOGRAFIA EDUCATIVA À BIOGRAFIA MÚSICO-EDUCATIVA}

O conceito surgiu na década de 1980 quando o movimento histórias de vida em formação eclodiu e revolucionou a concepção tradicional de formação, possibilitando aos sujeitos a apropriação de seus processos de formação, tornando-os autores de suas histórias (Passeggi, 2014). Foi nesse contexto que, ao lado de Gaston Pineau e Marie-Christine Josso, Pierre Dominicé despontou como um dos “[...] pioneiros do movimento [...] no âmbito da formação continuada" (Passeggi, 2014, p. 15). A partir de estudos realizados no âmbito do Grupo de Investigação sobre Adultos e seus Processos de Aprendizagem (GRAPA), integrado, também, por Matthias Finger e Marie-Christine Josso, criou-se a biografia educativa como ferramenta metodológica, utilizando-a em seus cursos-seminários ministrados na Universidade de Genebra. Desde então, Dominicé consideraa importante para a formação de adultos, sujeitos de suas próprias biografias, já que os ajuda a compreender os momentos de aprendizagens em suas vidas. Esses adultos, em uma busca constante por significação para diferentes situações vivenciadas, acabam reconhecendo que muitas influências interagem no curso de suas vidas e, assim, em suas aprendizagens (Dominicé, 2000).

A biografia educativa desenvolve-se no decorrer de três etapas reflexivas indispensáveis para o trabalho biográfico (Josso, 2010c), a maior parte das atividades destinadas à compreensão do processo de formação ou de conhecimento. Tais etapas foram organizadas e aplicadas em um estudopiloto, que antecedeu a criação da biografia músico-educativa, desenvolvido em um curso-seminário de férias para um grupo de quatro alunos do cursocampo da pesquisa (Almeida, 2019). Assim, o conceito biografia educativa foi 
introduzido ao longo de três encontros com duração de duas horas (Primeira Etapa); depois, diferentes atividades foram realizadas durante outros três encontros com o objetivo de produzir uma narrativa oral, que foi socializada com o grupo (Segunda Etapa). Por fim, previa-se elaborar uma narrativa escrita, depois, a biografia educativa seria interpretada individualmente e uma última versão dessa escrita seria socializada com o grupo na terceira e última etapa do trabalho biográfico, etapa que não foi concluída por vários motivos, ${ }^{4}$ entre eles, a desmotivação dos grupos e a indisponibilidade para realizar o último encontro.

Vale destacar que a biografia educativa apresenta-se, no contexto do ensino superior, como uma valiosa ferramenta, não só por buscar compreender os sujeitos em seus cotidianos passados e atuais, como devido ao conhecimento, segundo Dominicé, de uma verdadeira teia de vida na qual as pessoas se afetam e se movimentam em contextos sociais. Também, oferece a possibilidade de empoderamento individual, tendo em vista a interpretação colaborativa e contextual de suas narrativas. Por esse motivo, a biografia educativa é entendida como uma experiência capaz de promover autonomia à formação dos indivíduos, tornando-os sujeitos-autores (e atores) de sua própria trajetória acadêmica e profissional, capaz de conscientizá-los e de responsabilizá-los sobre suas trajetórias e escolhas.

Em suma, pode-se caracterizar a biografia educativa como uma aventura por entre a história de uma vida buscando investigar, nas memórias dos sujeitos, as pessoas, as relações, as cenas, as músicas, as imagens, os significados; tudo aquilo que de alguma maneira formou o sujeito e se fez por ele conhecido. Nesse emaranhado de histórias, os sujeitos contam episódios selecionados de suas vidas, considerando o momento em que vivem e os contextos para os quais as biografias educativas são produzidas, tanto tendo em vista os objetivos do projeto de formação, quanto a partir do contato com os outros narradores-ouvintes que o acompanham nesse processo.

Porém, ao desenvolver biografias educativas com acadêmicos de um curso de Licenciatura em Música, campo da pesquisa, tal procedimento metodológico revelou alguns desafios. Entre eles, pode-se destacar a proximidade pesquisadora-sujeitos, a duração do procedimento, a distância entre as leituras levadas para o debate e a realidade dos acadêmicos e o aprisionamento das narrativas ao visar o estímulo à construção de biografias educativas por meio de questionamentos. Por essas e outras razões, a biografia músico-educativa foi criada.

\footnotetext{
${ }^{4}$ Esses motivos foram problematizados na pesquisa de doutorado (Almeida, 2019) e resultaram em mudanças consideráveis no procedimento metodológico biografia músico-educativa. Neste artigo, objetiva-se apresentar o procedimento em seu formato final, porém cabe ressaltar que os caminhos percorridos para que se chegasse a esse novo formato serão discutidos em publicação futura.
} 
Além disso, a leitura crítica sobre dinâmicas de pesquisa e formação de adultos semelhantes à biografia educativa colaborou apontando possiveis desafios e contribuições do procedimento à pesquisa e à formação dos sujeitos. O que difere, essencialmente, a biografia músico-educativa das metodologias de pesquisa e formação estudadas em Educação (Abrahão, 2011; Delory-Momberger, 2006; Josso, 2010c; Nacarato; Passeggi, 2013; Passeggi, 2002; Peres, 2008; 2010; 2011) é a memória centrada na música. Aquela que marca, que transforma, que leva a vida para outros rios, que desenha modos de ser músico, ser estudante de música e professor de música.

Com o olhar voltado para a sociologia da música, entende-se que cada uma dessas memórias vem carregada de significações, tradições, relações, e é isso que a biografia músico-educativa procura estudar. Assim, por um lado, visa-se conscientizar os sujeitos de suas trajetórias formativas com a música, por outro, busca-se um alargamento das interpretações sobre as músicas da vida para além de seus aspectos técnico-musicais.

De forma resumida, a biografia músico-educativa, como procedimento metodológico, organiza-se em cinco etapas: um pré-momentos e outros quatro momentos. Esses momentos serão descritos, a seguir, tomando como base a primeira experimentação do procedimento no âmbito de uma pesquisa de doutorado (Almeida, 2019).

\section{PRÉ-MOMENTOS}

Consistiu no estabelecimento de acordos e explicações iniciais para participação na pesquisa/projeto de formação. Esse primeiro contato foi realizado com todos os alunos de um curso Licenciatura em Música e deu-se via rede social Facebook, aplicativo WhatsApp, e-mail e pessoalmente. Tendo em vista o tempo necessário para engajamento na pesquisa, essa foi registrada na instituição em que se desenvolveu e gerou carga horária curricular para os alunos. No final dos pré-momentos, dezesseis acadêmicos manifestaram interesse e disponibilidade para participar da pesquisa e foram organizados em três grupos: um composto por seis participantes, todos calouros, e o segundo e o terceiro contendo, cada um, cinco alunos que já estavam na metade do curso, sendo que um dos participantes de cada um desses dois grupos não pôde participar nas datas combinadas com os demais. Além de organizá-los a partir da etapa do curso em que cada participante se encontrava, observou-se, em geral, as inter-relações entre os integrantes, visando criar uma atmosfera de confiança entre eles.

\section{PRIMEIRO MOMENTO}

Provocação para iniciar uma narrativa musical individual organizada a partir de uma performance, de música(s), fotografia(s), imagens ou artes visuais, podendo ser lida ou narrada livremente no primeiro encontro 
presencial (segundo momento). Para a pesquisa de doutorado, essa fase inicial foi realizada pela pesquisadora via aplicativo WhatsApp e pessoalmente, de forma individual. Nessas interações, os participantes puderam esclarecer dúvidas e observou-se a ruptura de uma relação tradicional entre professora e alunos, na qual os participantes buscariam atender às expectativas da pesquisadora. Isso foi possivel graças à animação e insistência para que as narrativas musicais assumissem características dos próprios narradores: incentivou-se a utilização de diferentes recursos (fotografia, imagens, músicas etc.), bem como a apresentação de maneiras distintas, fosse lendo uma narrativa escrita, guiando-se por tópicos, partindo de músicas ou falando livremente, por exemplo.

\section{SEGUNDO MOMENTO}

Primeiro encontro presencial reunindo cada um dos grupos. Nele, cada participante realizou sua narrativa musical oral e ouviu as narrativas dos demais (toda a produção foi gravada, transcrita e enviada ao grupo). Esse primeiro encontro presencial aconteceu na casa da pesquisadora e durou de duas horas e meia até quatro horas e meia. Realizar o encontro em um ambiente diferente do universitário mostrou-se uma vantagem comparada ao estudo-piloto realizado anteriormente com a biografia educativa. Para mencionar um exemplo, antes de iniciarem a apresentação das narrativas musicais, os participantes do terceiro grupo comentaram sobre como se sentiam no ambiente universitário, espaço de cobrança em que se encontravam naquela correria; um lugar carregado de memórias, nem sempre positivas.

Quanto às narrativas musicais, observou-se plurais organizações e manifestações da memória. Assim, uma das participantes guardava sob suas mãos um livro de hinos de sua igreja enquanto narrava sua história com a música marcada por oportunidades e incentivos presentes na comunidade evangélica. Outra organizou um compilado de músicas que marcaram sua história, nele guiando-se para realizar sua narrativa musical. E um terceiro contou toda a sua história na música, finalizando-a com uma canção de Milton Nascimento que, metaforicamente, representava os sentidos da música para si - canção que foi cantada e tocada pelo participante. Esses são alguns exemplos da diversidade narrativa possibilitada pelo segundo momento da biografia músico-educativa.

\section{TERCEIRO MOMENTO}

Leitura individual das transcrições das narrativas para correções e reflexão, buscando pontos consonantes e possiveis novas memórias suscitadas a partir da leitura. Durante os quinze dias nos quais essa atividade foi realizada individualmente pelos participantes, era comum o 
contato entre esses e a pesquisadora, que tirava dúvidas sobre a pertinência da atividade e os orientava.

\section{QUARTO MOMENTO}

Segundo encontro presencial em grupo para conversação sobre as percepções refletidas no terceiro momento. Aqui, foram apresentadas novas provocações, visando desenvolver debates sobre temáticas emergidas das narrativas musicais. No final, a produção foi transcrita como uma narrativa entrelaçada, na qual a discussão cruzada resultou nos primeiros processos de conscientização sobre as experiências narradas. Por fim, no mesmo encontro, solicitou-se a escrita de uma biografia músico-educativa, que reuniu a revisitação sobre a primeira narrativa oral, a conscientização e novas memórias provocadas nas narrativas entrelaçadas e a avaliação sobre a participação nos quatro momentos que compõem o procedimento biografia músico-educativa.

Esse último encontro presencial mostrou-se rico e nitidamente formador, onde, nas conversas de cada um dos grupos, foram recorrentes os momentos em que um participante via-se na história do outro, ou dava-se por conta da pertinência de alguns episódios narrados, ou de características pessoais emergidas para a sua formação. Também foi a primeira oportunidade que tiveram para conversarem, entre acadêmicos, sobre o curso, o que revelou percepções semelhantes entre os diferentes grupos e serviu, também, para que identificassem dificuldades gerais experienciadas - que até então eram vistas por alguns participantes como desafios vividos apenas por eles.

Essas percepções sobre a narrativa entrelaçada foram refletidas pelos próprios participantes, que em suas biografias músico-educativas escritas, produção final do procedimento, destacaram a consciência da consciência (Josso, 2010a) sobre algumas memórias suscitadas no decorrer das atividades que, em alguns casos, só foi possivel por terem assistido a outros colegas narrando histórias com a música e refletindo sobre elas. Assim, a valorização da experiência problematizou e ampliou o conceito de formação, entregando "ao próprio sujeito o encargo de seus procedimentos de formação e a definição de suas necessidades” (Delory-Momberger, 2014, p. 90).

Por outro lado, entende-se que a formação mobilizada pela participação na pesquisa ou em um projeto de formação a partir da biografia músico-educativa pode ocorrer, também, a longo prazo, quando as experiências conscientizadas e as novas experiências promovidas pela participação na pesquisa/projeto se manifestarem em um saber-fazer, em uma avaliação, em escolhas, em novas representações, ou seja, demanda um processo de amadurecimento que se dá, naturalmente, em um tempoespaço futuro. 
Resumidamente, a biografia músico-educativa desencadeou uma primeira conscientização sobre processos formativos, no sentido de que os participantes perceberam a maneira como a música significa suas escolhas na graduação. Isso foi possivel porque essa nova organização permitiu aos participantes e à pesquisadora um acesso progressivo aos diferentes horizontes de compreensão sobre as narrativas de cada um e, posteriormente, do grupo. Pouco a pouco, os participantes se conheceram a partir de um novo olhar sobre si e dos olhares dos outros, que, vindos de outras perspectivas e histórias de vida, potencializaram as interpretações sobre a memória. Ao mesmo tempo, tiveram a oportunidade de discutir sobre desafios e problemas enfrentados no curso e sobre estratégias utilizadas para enfrentá-los. Em um ambiente de confiança, até porque a constituição de cada grupo respeitou questões de afinidades, permitiram-se refletir criticamente sobre suas posturas no curso, sobre as relações entre docentes e acadêmicos e sobre os distanciamentos entre suas histórias de vida e o atual currículo do curso, campo da pesquisa, por exemplo.

\section{CONSIDERAÇÕES}

É fundamental salientar a relevância de trazer a música para o centro da investigação sobre si e entendê-la nos contextos de diferentes pesquisas. Entende-se que a música pode ser uma facilitadora do processo formativo entre os sujeitos imersos na música, tornando o processo narrativo, por exemplo, mais natural e próximo de si.

A biografia músico-educativa aproximou os acadêmicos de relações que estabeleceram com a música no decorrer de suas vidas, fazendo a música falar por si, mas nem por isso ignorando outros elementos fundamentais na dinâmica de vida de cada um. A música foi um ponto de partida e, também, de chegada: partida como provocação, organização de uma primeira narrativa individual; chegada por compreender, também, o presente, o processo formativo vivido no curso-campo da pesquisa. As narrativas musicais foram iniciadas com a música e irradiadas para outros aspectos tão importantes quanto a música na formação dos sujeitos, além de terem sido, em alguns casos, espinha dorsal da trajetória de uma vida inteira.

Através desse estudo (auto)biográfico, foi possivel defender a teoria de que a elaboração e o estudo de biografias músico-educativas no ensino superior desencadeiam a conscientização sobre as inter-relações entre experiências pessoais e experiências acadêmico-formativas, esta delineando novas perspectivas sobre processos formativos. Dessa forma, a educação musical pode beneficiar-se desse novo procedimento metodológico para estudar relações plurais com a música e com o ensino musical e suas implicações na formação e atuação de educadores musicais.

Somada a essa questão, salienta-se a urgência não só em questionar e discutir as heranças conservatoriais nos cursos de música, como também 
em investigar e apontar caminhos que, longe de serem entendidos como únicos, possam alimentar as possibilidades metodológicas no ensino superior, visando a um ensino mais engajado, interdisciplinar, intersubjetivo e autônomo.

\section{REFERENCIAS}

ABRAHÃO, Maria Helena Menna Barreto. Pesquisa (auto)biográfica - tempo, memória e narrativas. In: ABRAHÃO, Maria Helena Menna Barreto (Org.). A aventura (auto)biográfica. Porto Alegre: EDIPUCRS, 2004. p. 201-224.

. Memoriais de formação: a (re)significação das imagens-

lembranças/recordações-referências para a pedagoga em formação.

Educação, Porto Alegre, v. 34, n. 2, p. 165-172, 2011.

As narrativas de si ressignificadas pelo emprego do método autobiográfico. In: SOUZA, Elizeu Clementino de; ABRAHÃO, Maria Helena Mena Barreto (Orgs.). Tempo, narrativas e ficções: a invenção de si. Porto Alegre: EDIPUCRS, 2016, [s.p.]. E-book.

ABREU, Delmary Vasconcelos de. Tornar-se professor de música na educação básica: um estudo a partir de narrativas de professores. 2011. Tese (Doutorado em Música) - Universidade Federal do Rio Grande do Sul, Porto Alegre, 2011a.

. Compreender a profissionalização de professores de música:

contribuições de abordagens biográficas. Opus, Porto Alegre, v. 17, n. 2, p. 141-162, 2011b.

. Politica educacional para o ensino de arte em SINOP: narrativas de professores sobre inserção profissional na área de arte/música. Revista Educação Cultura e Sociedade, v. 1, n. 2, p. 203-218, 2011 c.

- Narrativas de profisssionalização docente em música: uma epistemologia política na perspectiva da Teoria Ator-Rede. Revista da ABEM, Londrina, v. 23, n. 35, p. 125-137, 2015.

. História de vida e sua representatividade no campo da educação musical: um estudo com dois Educadores Musicais do Distrito Federal. InterMeio, Campo Grande, v. 23, n. 45, p. 207-227, 2017.

ALMEIDA, Jéssica. Biografia músico-educativa: produção de sentidos em meio à teia da vida. 2019. 368f. Tese (Doutorado em Educação) Universidade Federal de Santa Maria, Santa Maria, 2019.

ALMEIDA, Jéssica de; LOURO, Ana Lúcia. Narrativas de professores de música: entrelaçando vivências com a música e seu ensino e a atuação na educação básica. Revista da ABEM, v. 24, p. 67-80, 2016. 
ALVES, Gislene de Araújo. A construção da identidade profissional de licenciandos e música da UFRN: um estudo de narrativas autobiográficas. 2015. Dissertação (Mestrado em Música) - Universidade Federal do Rio Grande do Norte, Natal, 2015.

ANDERS, Fernanda. Dançar na aula de música: "dá gosto de vir para o colégio". 2014. Dissertação (Mestrado em Educação) - Universidade Federal do Rio Grande do Sul, Porto Alegre, 2014.

BOLÍVAR, Antonio; DOMINGO, Jesus; FERNÁNDEZ, Manuel. La investigación biográfico-narrativa en educación: enfoque y metodologia. Madrid: La Muralla, 2001.

BRAGANÇA, Inês Ferreira de Souza. Sobre o conceito de formação na abordagem (auto)biográfica. Educação, Porto Alegre, v. 34, n. 2, p. 157-164, 2011.

CHIENÉ, Adele. A narrativa de formação e a formação de formadores. In: NÓVOA, António; FINGER, Mathias (Orgs.). O método (auto)biográfico e a formação. Natal: EDUFRN, 2010. p. 129-142.

CUNHA, Maria Isabel da. Os conceitos de espaço, lugar e território nos processos analíticos da formação dos docentes. Educação Unisinos, v. 12, n. 3, p. 182-186, 2008.

DELORY-MOMBERGER, Christine. Formação e socialização: os ateliês biográficos de projeto. Educação e Pesquisa, São Paulo, v. 32, n. 2, p. 359$371,2006$.

. Biografia e Educação: figuras do individuo-projeto. Traduzido por Maria da Conceição Passeggi, João Gomes da Silva Neto, Luis Passeggi. 2. ed. Natal: EDUFRN, 2014.

DOMINICÉ, Pierre. Learning from our lives: using educational biographies with adults. San Francisco: Jossey-Bass, 2000.

A formação de adultos confrontada pelo imperativo biográfico. Educação e Pesquisa, São Paulo, v. 32, n. 2, p. 345-357, 2006.

. O processo de formação e alguns dos seus componentes relacionais. In: NÓVOA, António; FINGER, Mathias (Org.). O método (auto)biográfico e a formação. Natal: EDUFRN, 2010a. p. 81-95.

A biografia educativa: instrumento de investigação para a educação de adultos. In: NÓVOA, António; FINGER, Mathias (Org.). O método (auto)biográfico e a formação. Natal: EDUFRN, 2010b. p. 143-153.

FAÇANHA, Tainá Maria Magalhães. Memórias de professores de Artes/Música: concepções, objetivos e "estratégias" na educação musical em escolas estaduais de educação básica em Belém - PA. 2017. Dissertação (Mestrado em Artes) - Universidade Federal do Pará, Belém, 2017. 
FIGUEIRÔA, Arthur de Souza. Construção de laços pelas experiências com as escolas Parque de Brasília: a história de vida de duas professoras de música. 2017. Dissertação (Mestrado em Música) - Universidade de Brasília, Brasília, 2017.

FONSECA, Eliane Cristina N. Ferreira. Bandas e fanfarras escolares: processos de ensino na preparação para o festival de bandas e fanfarras de Santarém (PA). 2016. Dissertação (Mestrado em Artes) - Universidade Federal do Pará, Belém, 2016.

GAULKE, Tamar Genz. Aprendizagem da docência de música: um estudo a partir de narrativas de professores de música da educação básica. 2013. Dissertação (Mestrado em Música) - Universidade Federal do Rio Grande do Sul, Porto Alegre, 2013.

JOSSO, Marie-Christine. História de vida e projeto: a história de vida como projeto e as histórias de vida a serviço de projetos. Educação e Pesquisa, v. 25, n. 2, p. 11-23, 1999.

. Caminhar para si. Tradução de Albino Pozzer. Porto Alegre: EDIPUCRS, 2010a.

. Experiências de vida e formação. Tradução de José Cláudio e Júlia Ferreira. Natal: EDUFRN, 2010b.

Da formação do sujeito... Ao sujeito da formação. In: NÓVOA, António; FINGER, Matthias (Orgs.). O método (auto)biográfico e a formação. Natal: EDUFRN, 2010c.

. Proceso autobiográfico de (trans)formación identitaria y de conocimiento de sí. Revista Mexicana de Investigación Educativa, v. 19, n. 62, p. 735-761, 2014.

Os relatos de histórias de vida como desvelamento dos desafios existenciais da formação e do conhecimento: destinos sócio-culturais e projetos de vida programados na invenção de si. In: SOUZA, Elizeu Clementino de; ABRAHÃO, Maria Helena Mena Barreto (Orgs.). Tempo, narrativas e ficções: a invenção de si. Porto Alegre: EDIPUCRS, 2016. Ebook.

LANI-BAYLE, Martine. Narrativas de vida: motivos, limites e perspectivas. Traduzido por Albino Pozzer e Maria da Conceição Passeggi. In: PASSEGGI, Maria da Conceição; ABRAHÃO, Maria Helena Menna Barretto (Orgs.). Dimensões epistemológicos e metodológicas da pesquisa (auto)biográfica. Natal: EDUFRN, 2012. p. 59-78.

LOPES, Mariana Fonseca. As dores e amores de tornar-se professora: minhas memórias de professora iniciante. 2014. Dissertação (Mestrado em Educação) - Universidade Federal do Rio Grande do Sul, Porto Alegre, 2014. 
LOURO, Ana Lúcia; ARÓSTEGUI, José Luís. Docentes

universitários / professores de instrumento: suas concepções sobre educação e música. Em Pauta, v. 14, n. 22, p. 35-64, 2003.

LOURO, Ana Lúcia de Marques e. Cartas de licenciados em música:

(re)contando o vivido para centrar a aula no aluno. Revista da ABEM, Porto Alegre, v. 20, p. 63-68, 2008.

LOURO, Ana Lúcia. Improvisando sobre um tema de Larrosa: diários de aula numa disciplina sobre a "narrativa de si" na pesquisa em Educação Musical. Educere et Educare (Impresso), v. 8, p. 479-497, 2013.

Repertórios musicais, práticas pedagógicas e temas de pesquisa: reflexões sobre ensino de pesquisa e música dentro de uma abordagem (auto)biográfica. Revista da Fundarte, Montenegro, v. 16, n. 31, p. 8-26, 2016.

LOURO, Ana Lúcia; TEIXEIRA, Ziliane L. de Oliveira; RECK, André Müller. Pesquisa em Música: reflexões sobre memórias musicais e dimensões da "experiência de si". Revista Digital do LAV, Santa Maria, v. 9, n. 1, p. 89102, 2016.

LOURO, Ana Lúcia; RECK, André Müller. Práticas musicais do cotidiano na Iniciação Científica: diários de pesquisa em ambientes religiosos cristãos. Revista Digital do LAV, Santa Maria, v. 10, n. 2, p. 200-212, 2017.

MACHADO, Daniela Dotto. Indicadores educacionais de desenvolvimento profissional da docência em música nos anos finais do Ensino Fundamental. 2014. Tese (Doutorado em Educação) - Universidade Federal de São Carlos, São Carlos, 2014.

NACARATO, Adair Mendes; PASSEGGI, Maria da Conceição. Narrativas autobiográficas produzidas por futuras professoras: representações sobre a matemática escolar. Ver. Ed. PUC-Camp., Campinas, v. 18, n. 3, p. 287-299, 2013.

NETO, Antonio Chagas. Tornar-se professor particular de violino: uma pesquisa biográfica. 2014. Dissertação (Mestrado em Música) - Universidade Federal da Bahia, Salvador, 2014.

NÓVOA, António (Org.). Vidas de Professores. 2. ed. Porto: Porto Editora, 1995a.

NÓVOA, António. Diz-me como ensinas, dir-te-ei quem és. E vice-versa. In: FAZENDA, Ivani C. A. (Org.). A Pesquisa em Educação e as transformações do conhecimento. Campinas: Papirus, 1995b. p. 29-41.

PASSEGGI, Maria da Conceição. A dimensão histórica do sujeito no processo educativo. In: CONGRESSO BRASILEIRO DE HISTÓRIA DA EDUCAÇÃO, 2., 2002, Natal. Anais [...]. Natal, 2002. 
Aproximaciones teóricas a las perspectivas de la investigación (auto)biográfica em educación. Tradução de Dora Lilia Marín Diaz. Revista Educación y Pedagogía, v. 23, n. 61, p. 25-39, 2011 a.

A experiência em formação. Educação, Porto Alegre, v. 34, n. 2, p. 147-156, $2011 \mathrm{~b}$.

Prefácio à edição em língua portuguesa: educação e reflexão autobiográfica. In: DELORY-MOMBERGER, Christine. Biografia e Educação: figuras do indivíduo-projeto. Traduzido por Maria da Conceição Passeggi, João Gomes da Silva Neto, Luis Passeggi. 2. ed. Natal: EDUFRN, 2014. p. 13-19.

PEREIRA, Julio Cesar Pires. Trajetórias musicais de acordeonistas: um estudo na licenciatura em música (UERGS). 2016. Dissertação (Mestrado em Educação) - Universidade Federal de Santa Maria, Santa Maria, 2016.

PERES, Lúcia Maria Vaz. Movimentos (auto)formadores por entre a pesquisa e a escrita de si. Educação, Porto Alegre, v. 34, n. 2, p. 173-179, 2011.

. Narrativas como "retalhos das imagens" (auto)formadoras: matriciamentos em movimento. Atos de Pesquisa em Educação, Blumenau, v. 3, n. 2, p. 309-322, 2008.

. Narrativas de si como "passeur" de sentido protagonizando a formaçao humana de professores. In: REUNIÃO ANUAL DA ANPED, 33., 2010, Caxambu. Anais [...]. Caxambu, 2010.

PINEAU, Gaston; LE GRAND, Jean-Louis. As histórias de vida. Tradução de Carlos Eduardo Galvão Braga e Maria da Conceição Passeggi. Natal: EDUFRN, 2012.

RASSLAN, Simone Nogueira. O sujeito-ator e a música na constituição de si: uma perspectiva narrativo - biográfica. 2014. Dissertação (Mestrado em Educação) - Universidade Federal do Rio Grande do Sul, Porto Alegre, 2014.

RECK, André Müller; LOURO, Ana Lúcia; RAPÔSO, Mariane Martins. Práticas de educação musical em contextos religiosos: narrativa de licenciandos a partir de diários de aula. Revista da ABEM, Londrina, v. 22, n. 33, p. 121-136, 2014.

SILVA, Maria Goretti Herculano. Ao tecer somos tecidos: (re)significando a docência na constituição do habitus em estudantes de Música Licenciatura. 2016. Tese (Doutorado em Educação) - Universidade Federal do Ceará, Fortaleza, 2016.

SOARES, Iuri Correa. Significados das aulas de música na escola: um estudo narrativo com duas estudantes do Ensino Médio. 2014. Dissertação (Mestrado em Educação) - Universidade Federal do Rio Grande do Sul, Porto Alegre, 2014. 
SOUZA, Solange Dourado da Silva. A educação musical nas narrativas de licenciandas de Pedagogia: vivências e ausências. 2013. Dissertação (Mestrado em Educação) - Universidade Federal do Mato Grosso, Rondonópolis, 2013.

TAVARES, Ibbertson Nobre. Experiências formadoras e habitus musical no Cariri cearense: a história de vida desvelando minha formação docente. 2017. 83f. Dissertação (Mestrado em Educação) - Universidade Federal do Ceará, Fortaleza, 2017.

TEIXEIRA, Ziliane Lima de Oliveira. Narrativas de professores de flauta transversal e piano no ensino superior: a corporeidade presente (ou não) na aula de instrumento. 2016. Tese (Doutorado em Educação) - Universidade Federal de Santa Maria, Santa Maria, 2016.

TORRES, Maria Cecília de Araújo Rodrigues. Identidades Musicais de Alunas de Pedagogia: músicas, memória e mídia. 2003. 176f. Tese (Doutorado em Educação) - Universidade Federal do Rio Grande do Sul, Porto Alegre, 2003.

. Entrelaçamentos de lembranças musicais e religiosidade: "quando soube que cantar era rezar duas vezes". Revista da ABEM, Porto Alegre, v. 11 , p. 63-68, 2004.

TORRES, Maria Cecília. Narrativas dos movimentos de uma tese: apresentar as entrevistadas e narrar o narrado. Ouvirouver, Uberlândia, v. 13, n. 2, p. 644-657, 2017.

WEBER, Vanessa. Tornando-se professor de instrumento: narrativas de docentes-bacharéis. 2014. Dissertação (Mestrado em Educação) Universidade Federal de Santa Maria, Santa Maria, 2014.

WEISS, Douglas William Bonfante. A formação de professores de acordeom do Rio Grande do Sul: narrativas (auto)biográficas. 2016. Dissertação (Mestrado em Educação) - Universidade Federal de Santa Maria, 2015. 
Jéssica de Almeida é Professora do Curso de Licenciatura em Música e do Programa de PósGraduação em Educação da Universidade Federal de Roraima (UFRR). Doutora em Educação (Linha de Pesquisa Educação e Artes) pela Universidade Federal de Santa Maria, Mestre em Educação (2016) e Licenciada em Música (2012) pela mesma instituição. É membro do Grupo de Pesquisas Autonarrativas de práticas musicais (NarraMus) e co-líder do Grupo Musicologia na Amazônia (MusA) e pesquisa a formação e atuação de professores de música em diferentes contextos a partir de abordagens (auto)biográficas. É representante do estado Roraima na Associação Brasileira de Educação Musical (ABEM) e no Fórum Latinoamericano de Educação Musical (Fladem). https://orcid.org/0000-0002-0752-120X

Ana Lúcia Louro possui graduação em Bacharelado em Música pela Universidade Federal do Rio Grande do Sul (1991), mestrado em Música pela Universidade Federal do Rio Grande do Sul (1995) e doutorado em Música pela Universidade Federal do Rio Grande do Sul (2004). Atualmente é professora associada da Universidade Federal de Santa Maria. Tem experiência na área de Artes, com ênfase em Educação Musical, atuando principalmente nos seguintes temas: narrativas de si, educação musical, formação de professores, identidades profissionais e cursos superiores de música. É membro das associações ISME, ABEM, ANPPOM, ANPED, BIOGraph. https://orcid.org/0000-0001-8588-050X 